\title{
Participação da Sociedade na Definição dos Rumos da Escola Pública: manter ou eliminar a reprovação?*
}

\author{
VALDELAINE MENDES \\ Professora da Universidade Federal de Pelotas/RS \\ val@ufpel.tche.br
}

\begin{abstract}
Resumo
Este artigo tem como objetivo analisar as conseqüências da participação da sociedade em uma política pública para a conservação ou modificação das formas de organização do ensino. A política pública analisada - Constituinte Escolar: escola democrática e popular - tinha como propósito contar com a participação da sociedade na definição de princípios e diretrizes da educação para a rede pública de ensino do Estado do Rio Grande do Sul. O estudo demonstrou que todo o processo de participação criou condições para a reflexão sobre a organização do ensino na rede estadual, porém isso não foi suficiente para produzir alterações mais significativas nas rotinas escolares.

Palavras-chave: participação, política pública, escola.
\end{abstract}

\section{Resumen}

Este artículo tiene como objetivo analizar las consecuencias de la participación de la sociedad en una política pública para la conservación o modificación de los modos de organización de la enseñanza. La política pública analizada - Constituinte Escolar: escola democrática e popular - tenía como propósito contar con la participación de la sociedad en la definición de principios y pautas de la educación para la red pública de enseñanza del estado de Rio Grande do Sul. El estudio demostró que todo el proceso de participación creó condiciones para la reflexión sobre la organización de la enseñanza. Sin embargo, eso no fue lo bastante para producir alteraciones más significantes en las rutinas escolares.

Palabras-clave: participación, política pública, escuela.

\begin{abstract}
The aim of this paper is to analyze the consequences of the society's participation in the public policy of maintaining or modifying the manners in which teaching is organized. The public policy analyzed - Constituinte Escolar: escola democrática e popular - aimed at bringing together society in defining educational principles and policies for public teaching in the state of Rio Grande do Sul. The study showed that the whole participation process created conditions for a reflection about the teaching organization; however that was not enough to produce more significant changes in the school routines.
\end{abstract}

Key words: participation, public policies, school.

*Este artigo é parte integrante da Tese de Doutorado da autora (Mendes, 2005). 
O presente artigo tem como objetivo analisar a participação da sociedade em uma política pública cuja finalidade era a definição de princípios e diretrizes da educação para a rede pública de ensino do Estado do Rio Grande do Sul, implementada na gestão de Olívio Dutra (19992002). Pretende-se aqui discutir as conseqüências dessa participação na manutenção ou modificação nas formas de organização do ensino. Essa política setorial - Constituinte Escolar: escola democrática e popular - inscreviase num projeto político mais amplo, que intentava pôr em prática uma nova forma de conceber as relações entre o Estado e o cidadão na gestão pública e pretendia ter, na "democracia participativa", o elemento definidor da formulação e implantação de políticas públicas.

Por meio de plenárias, seminários, painéis, encontros e conferências, essa política pública objetivou assegurar diversificados fóruns e espaços de debate e reflexão que conduzissem à formulação de propostas educacionais pela comunidade escolar. Esse processo, desenvolvido nas unidades de ensino, buscou possíveis consensos que levassem ao estabelecimento de princípios e diretrizes da educação de crianças, adolescentes e adultos da rede estadual de ensino do Rio Grande do Sul.

Além dos professores, pais, familiares, alunos e funcionários, foram convidados a participar dos momentos da Constituinte Escolar (CE) as organizações da sociedade civil e as instituições do Poder Público. Quanto aos funcionários e professores, é importante destacar que todos os chamamentos foram realizados por meio de convite e não por convocação, sendo opcional o comparecimento às atividades organizadas. Para que os alunos integrassem esse processo, podiam ser realizadas atividades, como reuniões e seminários, que poderiam ser contadas como dias letivos, desde que, além dos alunos, professores e funcionários estivessem envolvidos.

A reflexão sobre a prática, o conhecimento da realidade em que esses indivíduos estão inseridos e a participação das comunidades que circundam as inúmeras escolas da rede seriam o ponto de partida da CE. Era um processo que deveria partir das práticas pedagógicas concretas, tanto de educadores quanto de pais, funcionários e estudantes, analisando o contexto - tanto local quanto regional, estadual e nacional - em que as práticas acontecem e onde as escolas estão inseridas (Rio Grande do Sul, 1999, p. 3).

O sucesso e o êxito da política educacional aqui investigada, em todas as etapas de execução, dependiam fundamentalmente da participação das comunidades que circundam as escolas, bem como de seus usuários e dos profissionais da educação. Isso porque todo o delineamento da política deveria ocorrer por meio de um processo que contasse com a participação da sociedade na definição dos rumos e das diretrizes para a educação no Rio Grande do Sul. 
A legitimidade de uma política como a CE estava justamente na instalação de um processo orientado pelos princípios da democracia direta em conformidade com a democracia representativa formalmente praticada. Trata-se de um aprofundamento da democracia representativa denominada, nas últimas décadas, de democracia participativa. A implementação desses processos não é nada simples, dadas as tensões entre aqueles setores que defendem um maior envolvimento da sociedade nas decisões políticas e aqueles para os quais essa participação representa uma ameaça ao poder que detêm. Dessa forma, este artigo pretende problematizar, a partir dos dados levantados na referida investigação, a relação entre a participação da sociedade na CE e as possibilidades de mudanças na organização curricular das escolas da rede estadual de ensino do Rio Grande do Sul.

A metodologia adotada fundamentou-se na abordagem qualitativa, por meio da qual os passos do trabalho foram sendo construídos com os sujeitos participantes do estudo à medida que os dados eram levantados, e novas questões e indagações iam surgindo. A pesquisa foi desenvolvida, de 2001 a 2003, em dez escolas da rede estadual de ensino do Rio Grande do Sul. Foram também coletados dados nos órgãos da Secretaria de Educação.

Havia uma grande expectativa dos educadores no Rio Grande do Sul sobre o programa que seria implementado na educação gaúcha a partir de 1999, com a gestão petista. As experiências da administração pública desenvolvidas no município de Porto Alegre, que naquele momento já tinham quase dez anos, acirravam as expectativas para o que seria desenvolvido em nível estadual. O depoimento da professora Marlene ${ }^{1}$, da Escola Júlio Dutra, confirma esse fato e salienta os significados das mudanças curriculares promovidas naquela rede de ensino:

Ah! Não, a receptividade da escola no início foi assim, nós acreditávamos que... como em todo o magistério, né? Nós estávamos louquinhos pra que se começasse assim... curiosos sempre, assim... Com o exemplo de Porto Alegre, a gente entende que deu um pulo, quando houve essa educação por ciclos, quando houve toda essa mudança, né? Se vê as notícias sobre evasão, sobre repetência e tudo mais. Eu acho que todo o mundo tinha uma grande expectativa e uma grande ansiedade mesmo de que se começasse alguma coisa nesse sentido, em todo o Estado.

As referências teóricas do material sistematizado pela Secretaria de Educação/RS (SE) para a CE induziam claramente a uma superação da estrutura seriada do ensino nas escolas públicas. Entretanto, a partir da discussão e da reflexão sobre a sua realidade, as escolas tinham autonomia

1 Todos os nomes dos sujeitos entrevistados mencionados neste artigo são fictícios. 
para elaborar seus regimentos e, conseqüentemente, para optar ou não por mudanças na sua organização.

Poucas escolas aceitaram tal desafio. Em um universo de mais de 3 mil escolas no Rio Grande do Sul, apenas 62 optaram por mudanças substanciais. A organização seriada, tanto no ensino fundamental quanto no ensino médio, ainda prevalece no Estado. $\mathrm{Na}$ região onde se desenvolveu este estudo, apenas uma escola decidiu pela extinção da seriação. Embora a preocupação com a retenção de alunos e com os processos de avaliação tenha ganho destaque em vários momentos da $\mathrm{CE}^{2}$, parece que isso não foi suficiente para promover uma ruptura com um esquema tradicional de ensino na maior parte das escolas do Estado.

Desde a década de 50 do século passado, os elevados índices de retenção de alunos, especialmente nas primeiras séries do ensino fundamental, têm preocupado os educadores brasileiros, tanto pelo prejuízo à organização e ao funcionamento da educação quanto pelos efeitos negativos na aprendizagem dos alunos e suas conseqüências no âmbito pessoal, familiar e social. A constatação da grande reprovação de estudantes nas escolas públicas do país fez emergir o debate sobre o tema da promoção continuada (Barretto, Mitrulis, 2001).

Nas décadas de 1960 e 1970, alguns Estados do país flexibilizaram a organização curricular de suas redes de escolas e substituíram a estrutura das séries por níveis de ensino. Essas mudanças atingiriam fundamentalmente os primeiros anos do processo de escolarização. De acordo com Elba Barretto e Eleny Mitrulis (2001), os processos de progressão continuada ${ }^{3}$ colocados em prática até esse período tinham como inspiração os sistemas adotados nos Estados Unidos e na Inglaterra, cujas referências curriculares tinham forte influência comportamentalista e uma concepção linear e cumulativa do conhecimento.

Nesses países a progressão escolar nos grupos de idade homogênea foi historicamente considerada, antes de tudo, como uma progressão social a que todos os indivíduos, indiscriminadamente, tinham direito mediante a freqüência às aulas, independentemente das diferenças de aproveitamento que apresentassem. (Barretto, Mitrulis, 2001, p. 110)

A partir da década de 1980, com a abertura democrática e com todas as transformações que ocorreram no plano político, social e cultural,

2 Dois cadernos temáticos tratavam diretamente dessa questão. Esse debate também estava indiretamente presente em outros cadernos temáticos.

3 Uma análise detalhada dos processos de progressão continuada defendidos por educadores e implementados em algumas cidades e Estados desde a década de 1950 pode ser encontrada em Barretto e Mitrulis (2001). 
aflorou no Brasil o debate sobre a função social da escola. Os elevados índices de reprovação e evasão ainda registrados nas escolas públicas alertavam para a necessária revisão de um conjunto de procedimentos adotados pelos governos no setor educacional, com destaque para o papel da avaliação.

Nos debates no meio educacional, a tradicional idéia do domínio de uma determinada matéria como requisito para progredir dentro do sistema de ensino deu lugar a formas diferenciadas de conceber a organização das atividades escolares e o trato com o conhecimento. Nesse sentido,

a concepção do conhecimento em rede contribuiu para subverter a hierarquia dos tempos escolares, que havia servido de álibi para a reprovação, e pretendeu inaugurar um período de grande liberdade da escola e dos professores para construir e desconstruir o currículo. (Barretto, Mitrulis, 2001, p. 116)

Seguindo a matriz de interpretação da escola como espaço de formação do cidadão que vai muito além da transmissão de conhecimentos e técnicas, algumas administrações públicas experimentaram em suas redes mudanças substanciais na organização curricular. No início dos anos 1990, nas cidades de São Paulo, Belo Horizonte, Porto Alegre, entre outras, foi determinado que as escolas substituíssem a estrutura seriada de ensino pelos ciclos. Em linhas gerais, esses novos projetos educacionais tinham em comum o fim da repetência entre um ano e outro do processo de escolarização e o agrupamento dos alunos por faixa etária. Ao final de cada ciclo, a partir de uma avaliação do desenvolvimento do aluno, poderia haver a repetência do último ano do ciclo.

$\mathrm{O}$ direito de todos de permanecer na escola e progredir dentro da estrutura curricular sem o rótulo do fracasso pessoal confere aos ciclos uma dimensão claramente democrática. Essa flexibilidade no processo de ensino repercute no plano pedagógico (uma escola menos centrada nos conteúdos), no plano cultural (a escola como pólo de valorização da cultura) e no plano cognitivo (uma escola preocupada com a história de vida e com as vivências de cada um), resultando em uma configuração de escola mais inclusiva (Barretto, Mitrulis, 2001).

De maneira diferente das administrações anteriormente apresentadas, nas quais a implementação dos ciclos foi uma determinação das secretarias de educação, na gestão aqui analisada não houve qualquer imposição no que tange à organização dos currículos. Diante do fato de um percentual tão pequeno (menos de $5 \%$ ) de escolas terem escolhido romper com a estrutura seriada de ensino, vale problematizar a questão da opção ou não das secretarias de educação de indicar às escolas a adoção de uma estrutura curricular menos excludente e seletiva. 
Detectou-se no estudo que, mesmo com a oferta de condições (todo o processo de debate e reflexão sobre as práticas educativas propiciados pela $\mathrm{CE}$ ) que conduzissem a uma mudança mais significativa na estrutura curricular, permitir às escolas optar "espontaneamente" pela mudança não foi a melhor medida num processo que pretendia democratizar a educação e voltar-se fundamentalmente para os setores excluídos da sociedade.

É necessário lembrar que a participação na CE era opcional. Apesar do esforço da SE em convencer as escolas a participar do processo, percebeu-se que a adesão foi parcial e com níveis diferentes de envolvimento. Esse registro é importante porque, se entre as escolas que participaram ativamente do processo e examinaram sua função na sociedade foram raras as que optaram por mudanças mais significativas em suas estruturas, o que dizer daquelas que tiveram pouco ou nenhum envolvimento?

Assim, embora todo o material organizado pela SE apontasse para a superação de uma estrutura de ensino excludente e competitiva, todas as opções de mudança foram deixadas para as escolas. Na realidade, tudo ficou sob a responsabilidade das escolas, desde a participação nas diferentes etapas da CE à decisão por mudanças mais significativas nos programas de ensino.

Do ponto de vista de quem foi governo, a opção por não impor os ciclos deve-se a uma avaliação de que essa constitui uma alternativa importante para a educação, porém tem de contar com o apoio daqueles sujeitos que integram a comunidade escolar. De acordo com Luísa, representante do governo:

[...] nós avaliamos com a equipe das coordenadorias como nós encaminharíamos essa questão. Então, nós decidimos que por se tratar de uma questão tão complexa, numa rede como a nossa, nós não partiríamos imediatamente pra colocar os ciclos como uma alternativa imediata. Nós criaríamos as condições pra que as escolas e as comunidades conhecessem as diferentes propostas que nós temos. E que, lá no limite quando eles construíssem o seu projeto político-pedagógico, e se a escola percebesse e se tivesse acordo construído na comunidade, [...] nós estaríamos dando todo o suporte. [...] E foi por isso que nós tivemos 62 escolas que evoluíram pra ciclo. Mas uma decisão amadurecida, consciente e portanto qualificada. Porque nós sabemos que você mudar radicalmente, [...] num primeiro momento ter que tirar tudo do lugar, e aí se não tiver acordo..., logo ali na frente ela pode "fazer água", ou virar contra quem a propõe. Então, nós entendemos que é uma alternativa importante, mas ela tem que ser construída e ela tem que ter o compromisso daqueles que se encontram envolvidos.

É evidente que qualquer mudança na escola precisa contar com o compromisso dos segmentos que a compõem. No caso dos ciclos, implica 
romper com determinada concepção de ensino alicerçada em notas e pareceres para uma valorização do conhecimento e para uma busca permanente do aprendizado. No livro Reprovação escolar: renúncia à educação, Vitor Henrique Paro (2001) mostra como há na sociedade um apego à reprovação que não resulta de uma causa isolada, mas de um conjunto de fatores de naturezas diversas. Entre os educadores isso não é diferente; mesmo entre aqueles que apresentam um discurso progressista, a dificuldade para eliminar a reprovação da escola está presente. $\mathrm{O}$ autor utiliza quatro grupos de determinantes (socioculturais, psicobiográficos, institucionais e didático-pedagógicos) para explicar por que, mesmo em uma escola que já está organizada em ciclos, há tanta resistência à promoção automática.

Isso, de certa forma, ajuda a entender por que tão poucas escolas, ao ter a oportunidade de adotar um ensino mais democrático, romperam com a estrutura seriada do ensino durante o processo da CE. Talvez tenha faltado à $\mathrm{SE}$ promover mecanismos que assegurassem maior aceitação dos ciclos e ações mais consistentes sobre a necessidade de uma revisão nos critérios de avaliação.

Para assegurar o compromisso dos segmentos que integram as unidades escolares com uma educação inclusiva, é necessário convencê-los dos efeitos nefastos da reprovação na vida do educando. É preciso refletir sobre questões como: que valores, que conceitos levará da escola um sujeito que foi constantemente rotulado como incapaz de avançar e acompanhar seus colegas? O que de positivo esse tipo de ação agregará à sua personalidade em formação? Que percepção terá esse sujeito da própria escola?

De acordo com Paro (2001, p. 77), faz-se necessário implementar políticas com o propósito de suprimir a reprovação do interior da escola, que devem ser introduzidas

de forma democrática e acompanhadas de processos de conscientização a respeito de sua justeza e necessidade. Mas é imperioso também prever algum tipo de iniciativa que enseje aos atores envolvidos, especialmente educadores, refletirem sobre crenças e modificarem hábitos e condutas incrustados há muito tempo na maneira de ser e de agir de cada um.

Sem dúvida, a preocupação com a reprovação estava presente entre os gestores e nos documentos por eles organizados; porém, sua supressão do cotidiano das escolas não era uma meta a ser alcançada. Na análise dos depoimentos daqueles que eram integrantes do governo, parecia haver um certo receio do impacto, na opinião pública, de uma decisão mais radical sobre a organização curricular nas escolas. Na fala já citada de Luísa, 
transparece a idéia de que a opção pelos ciclos poderia não resultar em mudanças significativas na escola ou se voltar contra quem propõe. Parece que, ao deixar tal opção para as escolas, a responsabilidade sobre as conseqüências da decisão tomada recairia sobre a própria escola e não sobre o governo.

Se a opção da SE durante a gestão Olívio Dutra tivesse sido a de determinar às escolas a eliminação da reprovação, provavelmente haveria muita repercussão na grande imprensa no Estado. Isso talvez não resultasse em algo positivo para a popularidade da gestão em análise e, ainda, dificultasse a implementação de outros projetos, dada a imagem negativa que poderia ser construída sobre as ações dessa gestão na esfera educacional. Embora seja apenas uma suspeita, não-afirmada ao longo da coleta de dados, acredita-se que esse pressuposto foi levado em consideração.

Ao analisar os quatro anos da gestão, a professora Luísa avalia como positiva a decisão de não impor os ciclos, pois, na sua opinião, as escolas que os implementaram foram efetivamente aquelas que se dispuseram a mudar suas ações: então, essa foi uma decisão acertada da secretaria [...] porque nós vimos e sabemos que tem limites nos ciclos onde a Secretaria da Educação, mesmo se tratando do âmbito de uma prefeitura, não respeitou esse processo. Ai acontece que você tem um ciclo de fachada. Fica claro, nesse depoimento, que a escolha da promoção automática não tem um valor em si, depende de um conjunto de medidas.

Ao analisar os motivos que impediram um maior número de escolas de optar pelos ciclos, a professora Luísa lembrou o quanto é difícil mostrar aos pais a importância de uma avaliação processual. Afinal, vive-se em uma sociedade que exclui o tempo todo. Na sua opinião, para os pais, quanto mais reprova, melhor é o professor, e quanto mais disciplina exige, melhor é a escola.

[...] essa é uma questão ainda extremamente polêmica [...] porque toda a sociedade é competitiva, ela trabalha no processo de escolha dos melhores [...] e os pais, mesmo que não tenham um grau de escolaridade mais elevado, eles ainda tentam reafirmar que quanto mais exigente o professor é e quanto mais é cobrado o conteúdo, pura e simplesmente, numa avaliação que muitas vezes não é de processo, melhor é o professor. Então, tivemos que trabalhar com uma certa desmistificação do processo, pra que os pais compreendessem que uma avaliação ela compreende todos os processos, e não apenas uma prova, um método que o professor utiliza [...].

Para a professora Luísa, essa postura dos pais não é diferente no interior da escola. As escolas, na maior parte das vezes, incentivam a competição entre seus alunos, transformando a avaliação em um processo 
que serve para classificar e rotular alunos como bons ou maus. Além de estabelecer tal distinção, confere uma punição àqueles que enquadrou como piores e uma premiação para aqueles que classificou como melhores.

[...] por mais que a constituinte tenha dado conta disso, mas tu não muda uma cultura de uma hora para outra. E as próprias direções das escolas, elas trabalham muito reforçando isso, na maioria dos casos porque elas querem ver a sua escola diante das outras, como aquela que de fato tem a disciplina e portanto os alunos têm que tá competindo entre eles pra obter as melhores notas. Os professores trabalham também nessa direção. E os pais vão [...] adaptando a isso.

Para a professora, esse debate está na essência da qualificação do ensino. Não dá para discordar dessa opinião da professora. De fato, pensar uma outra organização curricular exige romper com um conjunto de conceitos já estabelecidos na sociedade e incorporados tanto pelos educadores quanto pelos pais. Isso significa recorrer a uma visão de ensino menos competitiva e excludente, cujos mecanismos não neguem a condição de sujeito do educando.

Entretanto, se o caráter da educação predominantemente aceito na sociedade acentua a importância da reprovação como valor intrínseco ao processo educativo, não dá para supor que as escolas fossem "espontaneamente", durante o processo da CE, adotar a promoção automática em seus projetos pedagógicos. Somente uma concepção mais avançada de educação de um coletivo de educadores permite que sejam criadas as condições em uma escola para uma opção espontânea dessa natureza. É justamente por essa concepção de educação não estar presente na maior parte das escolas brasileiras que, no caso do Rio Grande do Sul, apenas 62 adotaram os ciclos em suas organizações.

De acordo com Paro (2001, p. 61),

se, por um lado, não se deve acreditar na eficácia e mesmo na legitimidade de se combater a tendência à reprovação "por decreto", como imposição - pois só como componente de uma visão avançada de educação, que nega a submissão e adota a motivação intrínseca no ensino, ela pode se firmar-, por outro lado, não é possível, nem lógico, acreditar que qualquer concepção avançada de educação possa omitir o cuidado com a superação da negação do sujeito que a prática da reprovação encerra.

Se prevalece na sociedade uma visão de educação punitiva, classificatória e competitiva, conforme afirmou a gestora Luísa, não teria sido mais adequada uma ação do Estado inibidora de práticas dessa natureza? 
Um debate qualificado foi realizado na Escola Paulo Borges, única a optar pelos ciclos na região abrangida pela Coordenadoria Regional de Educação (CRE) onde foi realizado este estudo. Das escolas investigadas, essa foi uma das que participou mais ativamente da CE. O conhecimento mais detalhado da realidade, propiciado nas primeiras etapas do processo, conduziu a um movimento na escola para a revisão dos mecanismos de avaliação e de organização do ensino. Como expressa a professora Ana, a opção pelos ciclos foi conseqüência do diagnóstico sobre o cotidiano da escola:

Foi uma conseqüência, os ciclos acabou sendo uma conseqüência. Não tem como explicar isso direito, porque as discussões elas iam acontecendo e se acumulando. Como é que a gente ia voltar atrás? Depois te tu conhecer, não tem mais como tu fechar os olhos, fazer de conta que tu não sabes [...].

Para a professora Maria, da mesma escola, talvez nem precisasse da $\mathrm{CE}$ para perceber a necessidade de mudança no interior da escola. O próprio cotidiano fornece elementos que indicam a necessidade de revisão das ações. Entretanto, foi o processo da CE o desencadeador da implementação dos ciclos que, por sua vez, conduziu a outras mudanças.

Muita coisa podia ter sido feita sem ter ciclo. Eu fico assim meio confusa, às vezes, quando eu falo, porque não foi o ciclo, muitas mudanças que aconteceram já podiam ter acontecido antes. Mas o ciclo acho que deu essa oportunidade, porque a gente tinha vontade de fazer e não se fazia, né? Tava tudo aquela coisa tradicional, não tinha tudo isso que aconteceu depois do ciclo. Mas eu acho que aconteceram muitas mudanças.

A professora revelou o quanto a incomodava a reprovação de um grande número de alunos em matemática, disciplina que ministra. Entretanto, sempre buscava argumentos para justificar tal problema. Fica claro, no trecho a seguir, que a opção pelos ciclos necessariamente tem de ser acompanhada por reformas estruturais. A criação dos laboratórios de aprendizagem e a garantia de carga horária para atender os alunos com dificuldade no turno inverso permitiram uma qualificação do trabalho, reconhecida pelos próprios alunos. Nesse caso, as mudanças ocorridas foram conseqüência da opção pelos ciclos.

Pra mim, como professora de matemática, são muito boas, por exemplo, quanto à avaliação, as mudanças que aconteceram na avaliação, né, quanto à parte do laboratório de aprendizagem. Porque era muito cômodo, por exemplo, o professor de matemática [...], tem 30 alunos, vão reprovar 8 alunos ou 7. E isso me preocupava, isso me angustiava [...] Todo mundo tem condições de aprender, todo 
mundo podia ter aprendido. Mesmo antes de ter o ciclo eu sempre me preocupei com essa história, daquele aluno que ficou, que reprovou. Mas por quê? A culpa é minha, a culpa é dele, ficava procurando um motivo, né. Mesmo que eu tivesse aquela preocupação, eu não podia fazer muita coisa, porque eu não tinha aquele tempo pra dar pra aquele aluno. E agora, com o laboratório de aprendizagem eu tenho. E aquele aluno que tem dificuldades, que eu achava que ele tinha condições, e que eu não tinha nem aquele momento, agora eu tenho um laboratório, que eu posso trabalhar com aquele aluno e ele acompanha, né. Eu tava dizendo que eles fizeram uma auto-avaliação. E eu fiquei muito satisfeita com a auto-avaliação que eles fizeram: ah, professora, agora eu aprendi tudo [...].

Para que os ciclos pudessem ser implementados, os professores da Escola Paulo Borges tiveram redução da carga horária de trabalho em sala de aula para disporem de mais tempo para estudo sobre as modificações por que passava a escola. Tal estratégia contou com o apoio da CRE. O professor Darlan, diretor da escola, falou dessa alteração:

Aqui, o máximo que a gente dá para o professor são 10 horas. A gente deixa 10 para que o professor possa, devido à implantação do nosso projeto, ter mais tempo para estudo, mais tempo para análise, mais tempo para discussão, para leitura de textos. A gente está aprendendo, então a gente precisa de muito subsídio pra que se possa errar o menos possível.

É evidente que a opção por uma mudança tão significativa na organização curricular precisa ser acompanhada da oferta de condições de trabalho condizentes com as novas demandas da escola. Essa é, talvez, uma das principais reclamações dos professores naquelas localidades onde os ciclos foram impostos pelas secretarias de educação, sem um suporte necessário para todas as dificuldades decorrentes de uma mudança dessa natureza.

A grande questão é que uma coisa não elimina a outra, ambas devem ser pensadas com a finalidade de propiciar o desenvolvimento integral do educando. De acordo com Moreira Leite (2003, p. 193), se um currículo adequado exige a promoção automática a recíproca é verdadeira. Tanto a promoção automática quanto as boas condições de trabalho são requisitos necessários para uma educação de qualidade. Não é porque se eliminou a reprovação da escola que são necessárias melhores condições de trabalho ou vice-versa. Uma coisa não prescinde da outra.

Ocorre que a oferta de boas condições de trabalho é necessária e deve ser reivindicada sempre, independentemente de alterações na organização curricular. A opção pela eliminação da reprovação dos currículos escolares precisa ser acompanhada de um processo de reflexão, debate e estudo sobre as novas demandas da escola. Isso é necessário para 
desconstruir determinadas práticas já incorporadas pelos educadores, para permitir que percebam o significado e a importância da promoção automática e para assegurar o compromisso com o novo processo.

Medidas decididas de forma autoritária nos gabinetes podem ser inúteis e ter resultados frustrantes se não contarem com esse envolvimento dos educadores. Qualquer política educacional que pretende efetivamente alcançar os objetivos a que se propõe precisa considerar a predisposição daqueles sujeitos diretamente envolvidos na sua execução (Paro, 2001; Moreira Leite, 2003).

Depois de muitos debates e discussões originados na CE, a Escola Paulo Borges optou pela alteração na organização curricular por reconhecer nos ciclos a possibilidade da inclusão. De acordo com a professora Ana:

[...] a nossa visão de ciclos aqui é em função da inclusão. É tá repensando que papel temos nós, professores, que deuses somos nós, que determinamos quem vai adiante na vida e quem não vai. Se todos vão, independente da escola, todos crescem, todos vão fazer 7 anos, 8 anos, 9, anos, 10 anos, não somos nós que vamos impedir. Aí, se eles vão tá compatíveis com os colegas deles, na mesma série ou no mesmo ciclo ou na mesma etapa do desenvolvimento na escola, bom, aí, é outra história. Agora que eles vão se desenvolver e que eles vão tá sempre aprendendo coisas, que eles vão tá sempre crescendo, vão. Ou nós vamos estar junto com eles, ou nós vamos estar contra eles...

Percebe-se também na fala da professora uma tentativa de superar uma visão presente na escola de que cabe ao professor, com os instrumentos de que dispõe, definir os rumos da vida dos alunos. Esse estar contra os alunos pode ser caracterizado, segundo Paulo Freire (1999), como uma relação do formador como o sujeito de uma relação na qual o aluno constitui o objeto.

Estar a favor dos alunos é permitir que eles se desenvolvam. É entender que discentes e docentes são sujeitos do processo educativo mesmo considerando suas diferenças e condições -, que ambos aprendem e ensinam, o que não significa ignorar os papéis de cada um no interior da escola. Assim, segundo Freire (1999), tanto na experiência docente quanto na discente, uma não se reduz à condição de objeto da outra.

É interessante destacar que todas as pessoas entrevistadas na Escola Paulo Borges parecem ter incorporado em seus discursos a visão de educação demonstrada pela professora Ana. A fala da merendeira Amélia expressa uma compreensão do caráter inclusivo que os ciclos têm no interior da escola pública: 
Eu acho assim, ó, que já tava na hora, porque tinha alunos que ficavam rodando, rodando naquelas matérias e depois já tavam ficando assim com uma idade meio avançada e tavam perdidos junto com os outros. E aí o que que acontecia? Eles saíam da escola. Nos ciclos segue trabalhando com ele, né?

A funcionária demonstra ter assimilado que a reprovação não é um procedimento positivo para o aluno que a experimenta. Até porque, se esse fosse um mecanismo tão eficaz, os alunos não repetiriam várias vezes uma determinada série como ocorre em muitas redes de ensino. Segundo Paro (2001, p. 111), é um total equívoco acreditar que é por meio de provas e da reprovação que o aluno encontra estímulo para o estudo porque, se isso for verdade, significa que o ensino está muito mal provido de recursos para motivar o aluno para estudar.

Mesmo que alguns não tenham muita clareza sobre quais alterações os ciclos produzem, parece haver consenso sobre a necessidade de modificar a escola. Porém, prevalece uma certa confusão sobre os caminhos a serem trilhados para alcançar tais mudanças.

Segundo Miguel G. Arroyo (2002, p. 161), uma nova organização vem carregada de dúvidas. Afinal, na organização seriada já sabemos o que fazer, cumprir as normas de enturmação, de avaliação, seguir as normas que predefinem quem passa de série e quem não passa. Nesse caso, o papel da CRE e da SE no acompanhamento e assessoramento do processo instalado na escola é imprescindível. Embora alguns entrevistados da Escola Paulo Borges tenham afirmado que houve autorização para a redução da carga horária dos professores e de novas contratações, parece ter faltado um acompanhamento mais sistemático das modificações que estavam ocorrendo na escola. A sensação de isolamento e da necessidade de dar conta dos próprios problemas foi constatada em vários depoimentos.

Um aspecto expresso na fala da professora Clara sobre a opção da escola pela superação do ensino seriado merece destaque: nós quisemos assim, não temos como voltar atrás. Não foi o governo quem determinou. Não podemos nem dizer que isso foi coisa do governo.

$\mathrm{O}$ fato de terem decidido coletivamente organizar a escola em ciclos parece não animar os sujeitos entrevistados a revelar qualquer tipo de resistência. A professora Clara chegou a chorar durante a entrevista, porque estava enfrentando muitas dificuldades com as mudanças ocorridas na escola. Mesmo sem se expressar verbalmente, percebe-se que ela teria um certo constrangimento em demonstrar resistência e contrariedade a algo que foi definido pela coletividade. $O$ choro e a fala parecem exprimir o conflito vivido pela docente entre aquilo que escolheu e as dificuldades que enfrenta. E, na sua percepção, diante das dificuldades, só resta buscar soluções, e não encontrar culpados. 
Parece que a responsabilidade pela mudança nas rotinas da escola, a partir da opção pelos ciclos, ficou concentrada nos docentes. Durante a investigação, percebeu-se, nesse segmento, uma maior preocupação com a revisão dos planos de ensino, com as mudanças nos processos de avaliação, com a reorganização da carga horária das aulas, etc. Disso, deduz-se que a concentração de esforços de todos os segmentos da escola foi maior na fase de decisão pela mudança na organização curricular do que no momento da sua implementação, em que as tarefas ficaram principalmente nas mãos dos professores. A análise dos dados levantados permite inferir que nem os professores nem os outros segmentos devem ser responsabilizados por esse quadro durante a etapa de implementação da modificação curricular. De fato, pode-se afirmar que foram as tradicionais rotinas escolares (em que os docentes centram todas as responsabilidades pelo processo pedagógico) que acabaram conduzindo os professores a buscar isoladamente soluções para as dificuldades enfrentadas.

O processo vivido pela Escola Paulo Borges é novo e, como tal, necessita da disponibilidade da comunidade escolar para enfrentar os problemas que surgem no dia-a-dia. Por ser, talvez, a única escola na região a trabalhar com ciclos, não há com quem compartilhar as dificuldades e faltam respostas às múltiplas dúvidas que surgem. Por outro lado, a ausência de uma estrutura universitária na cidade inviabiliza o diálogo com aqueles trabalhadores que atuam na formação de educadores. Por sua vez, a universidade também teria muito a aprender com essa experiência.

A professora Sueli destacou o inevitável aumento do volume de trabalho ocasionado pelas mudanças na escola. $\mathrm{O}$ processo de avaliação permanente exige uma dedicação maior do docente. Para Sueli: aquele professor que não quer trabalhar, troque de escola, porque não dá. Se tu ver o trabalho que tem uma professora, que nos mostrou ontem na reunião [...].

Além do aumento das tarefas docentes, destaca-se nos depoimentos como um problema a presença de uma certa confusão sobre o fim da reprovação. Apesar disso, segundo a professora Ana, a maior parte dos alunos compreendeu a sistemática dos ciclos:

[...] a maioria se responsabilizou mais pelo seu processo. Isso aí a gente tem sentido, eles pedem pra vir ao laboratório. [...] a avaliação tá sendo um acompanhamento diário, e eles tão fazendo esse acompanhamento também, né, do processo deles. Então, isso eu já senti, essa responsabilidade deles.

Embora haja um significativo compromisso do corpo discente com o novo processo, há um grupo de alunos que acredita que só a matrícula basta para progredir para a etapa seguinte. Nesse caso, não comparecem às aulas, ou quando apresentam dificuldades não comparecem ao reforço no 
turno inverso. Na escola, os educadores têm dúvidas sobre como lidar com esse aluno, e aí aparecem argumentos e expressões características do ensino seriado, como na fala da professora Ana: eles estão meio confusos como a gente, tá. Tem uns que a Sueli tá dizendo que eles não vão avançar, porque eles não vêm, porque eles acham que vão passar por osmose. [...] Eu acho que não dá para passar! Não sabe, não quer, não vem; como é que tu vai passar?

Mesmo na fala da professora Ana, que tem uma visão avançada de educação, percebeu-se uma preocupação com um possível rótulo que a escola ganhe, de lugar "onde todo mundo passa", o que, do ponto de vista educativo, seria extremamente positivo, já que é uma escola onde os sujeitos, na fase de formação da personalidade, não experimentam o fracasso e a negação da possibilidade de continuarem se desenvolvendo com o grupo de sua convivência. Seria melhor que a professora vibrasse com a possibilidade de a escola passar a ter esse estereótipo mais inclusivo.

Segundo a professora Sueli:

Eles não estão conseguindo, não vêm ao reforço e pensam que vão passar, eles acham: "eu vou passar", mas não é bem assim. O que a gente tem que botar na cabeça das pessoas, não é dizer vai passar todo mundo. E é o que muita gente imagina. Porque se não avançou, não avançou, o que que vai se fazer? Porque todo mundo tem aquela idéia que chegou aqui e vai passar, não é assim.

Nesse depoimento, parece que a escola fez "tudo que era possível", porém, se o aluno não provou estar em condições de ser aprovado, não o será. Durante as visitas à Escola Paulo Borges, percebeu-se que a professora Sueli estava montando um verdadeiro "dossiê" dos alunos que julgava sem condições de progredir para a etapa seguinte. Embora não se tenha tido acesso a esses pareceres da professora, constatou-se, durante as conversas na escola, que o conteúdo dos documentos voltava-se para a falta de interesse dos alunos, para o pouco entusiasmo com as aulas, para o nãocomparecimento à escola. A responsabilização do aluno por não ter aprendido parece ser acentuada nesse processo. A grande preocupação manifestada pela professora Sueli é com o fato de os alunos "passarem" e não com o "aprender".

A falta de interesse de alguns alunos, justificada com o discurso vou passar de qualquer jeito, é apontada como um dos principais problemas enfrentados pela Escola Paulo Borges. A aluna Rita, de 14 anos, ao analisar o comportamento dos colegas, comprova essa constatação: eu acho que tem muita gente que pensa: estando nos ciclos e em etapas, por conceito não vai rodar. Mas eu acho que roda. É só desinteressar que roda. 
Nessa visão dos alunos (que não é exclusiva desse segmento), fica evidente que a maior motivação para estudar está nas notas e no medo da reprovação. Como relata Rita, na ausência desses mecanismos torna-se desnecessário comparecer à escola. Para Barretto e Mitrulis (2001, p. 132), o estímulo para estudar, tradicionalmente, não está na vontade de aprender, mas sim nos constrangimentos historicamente criados pela própria escola ou na sua ligação com as exigências mais amplas do mercado de trabalho.

O homem assume a condição de sujeito de sua própria história quando dispõe do controle de sua vida e faz prevalecer suas vontades. No modo de produção predominante no mundo hoje, a não-propriedade dos meios de produção limita a condição de sujeito do homem. Na escola, a partir do momento em que os alunos aprendem a dar mais valor às avaliações externas, significa que estão aprendendo mais sobre aquilo que a sociedade espera deles do que a respeito do que gostam, desejam, sentem e precisam. Se, como afirma Paro em várias de suas obras, é necessário educar para o bem-viver, o olhar externo sobre a ação do aluno não pode sobrepujar sua própria avaliação, pois isso ameaça sobremaneira sua condição de sujeito.

Entretanto, a mesma aluna considera importante a extinção da reprovação, pois não imagina ser positivo estudar em uma escola que confere grande valor às provas. Além disso, ela revela a importância do aprender em detrimento do memorizar:

Acho que mudou muito, começando que... acho que essa etapa em ciclos, acho que foi a partir da constituinte. Foi uma nova forma que eles acharam de educar. [...] Eu acho que estudar numa escola onde os professores só dão prova, prova, o aluno tem que decorar a matéria; prova, prova, eu acho que isso daí fica muito cansativo, eu acho que o aluno não deve aprender só fazendo prova e decorando e sim no diaa-dia.

Vale ressaltar que Rita foi umas das representantes discentes da escola na CE e teve, por isso, um contato maior com os debates sobre os efeitos da reprovação na vida dos alunos.

Apesar dessa dificuldade revelada por alguns para assimilar um ensino sem reprovação, em muitas falas foi possível identificar uma maior preocupação com o "aprender". Uma professora declarou que há uma demanda do corpo docente para entender melhor como o aluno aprende, como se desenvolve. Ao referir-se à avaliação, a professora Maria afirmou: [...] a avaliação pra mim é muito mais pra saber onde eles estão, o que que na verdade eles conseguiram aprender, do que a nota em si. 
Se, por um lado, a nota permanece sendo a referência para alguns educadores nessa escola, por outro, muitos passaram a dar maior importância ao aprendizado do aluno e ao domínio de determinados componentes culturais em detrimento dos conceitos.

Em relação aos pais, parece ter havido dois tipos de interpretação sobre a opção pelos ciclos. Para uns, era a possibilidade de ver seus filhos avançarem, deixando de permanecer por vários anos na mesma série, experimentando o fracasso de ter de repetir mais um ano na escola. Para outros, era a desqualificação do ensino pela ausência da reprovação, como se a adoção da promoção automática dentro dos ciclos fosse comprometer o aprendizado dos alunos.

Em uma avaliação sobre o comportamento dos pais em relação aos ciclos, a professora Ana afirmou: tem uns que tiraram os filhos daqui; outros botaram: ah, eu vou botar nessa escola, pode ser que ande agora. Então, nós temos os dois tipos, né?

Um aspecto detectado nas falas é que, com a implementação dos ciclos, a reprovação deixa de ser o grande problema da escola para dar lugar ao debate sobre outras questões. Isso foi mais facilmente detectado na Escola Paulo Borges, na relação dos pais com a escola. A professora Clara revelou não saber como lidar com essas outras coisas. Exemplificou com a fala de um pai que foi até a escola e disse: eu não posso mais com o meu filho. É óbvio que a

introdução da promoção automática implica uma transformação radical na escola, na medida em que professores e alunos passarão a viver em torno de outros valores $e$ aspirações. Está claro que não podemos saber, antecipadamente, quais os problemas que essa nova estruturação irá apresentar; podemos, entretanto, delimitar as suas características mais gerais. (Moreira Leite, 2003, p. 193)

Provavelmente, a ênfase no diálogo, ocasionada pelo processo de debate da $\mathrm{CE}$, tenha permitido à família sentir-se mais à vontade para expor seus problemas com os educadores da escola. Para estes, essa maior aproximação da família com a escola (extremamente positiva) tem constituído motivo de preocupação, pois não sabem como agir perante determinadas situações. Percebe-se que a "nota" deixa de ser o foco principal da escola para dar lugar a outras preocupações.

Das dez escolas pesquisadas, a Paulo Borges foi evidentemente a que mais demonstrou disposição para mudar sua organização curricular. Entretanto, a preocupação com os índices de reprovação e de repetência também foi percebida em outras escolas. 
A Escola Gilberto Alves, mesmo tendo optado coletivamente por interromper a participação no processo da CE a partir da indicação do Centro dos Professores do Estado do Rio Grande do Sul (CPERS) Sindicato dos Trabalhadores em Educação ${ }^{4}$, ao elaborar o regimento e o projeto pedagógico seguiu as orientações dos documentos distribuídos pelo governo para a CE. Segundo o professor Gustavo: muito embora a gente não tenha participado diretamente, os princípios são os mesmos e o processo foi o mesmo, só que de uma forma mais independente.

Assim, a escola decidiu rever sua organização curricular e optou por implantar a progressão parcial. Os motivos da escolha da progressão parcial e como essa ocorreu estão sintetizados neste trecho da fala do professor Gustavo:

[...] nossa opção foi pela progressão parcial. Então, a idéia de progressão parcial e o que a gente tem estimulado a comunidade, é exatamente nesse sentido; quer dizer, não vê assim como se estivesse forçando a barra para aprovar. [...] Há também essa preocupação na nossa escola, no sentido de diminuir a repetência, diminuir a evasão escolar também, até por uma questão de estímulo. Até para que os alunos possam se recuperar. Então, nós implantamos esse ano a progressão parcial. $O$ aluno que foi reprovado em até duas disciplinas tem direito de cursar a série seguinte e fazer a progressão parcial paralela num outro turno.

Tal trabalho parece ter mudado a rotina da escola, de forma a evitar a retenção do aluno em uma série. Da parte dos professores, parece haver uma preocupação maior com o aprendizado dos alunos. Sobre essa questão, o professor Gustavo revelou:

Nós estamos trabalhando; assim, o aluno deverá progredir. Os próprios professores também foram construindo essa questão da progressão, de uma forma que o professor possa focalizar o problema do aluno, [...] é um estudo mais particularizado; tu vais trabalhar com um grupo menor e tu vais trabalhar no detalhe.

Com relação ao envolvimento da comunidade na opção pela progressão parcial, o professor revelou ter havido a participação de todos os segmentos, embora essa prática não fosse tradicional na escola. Atribuiu essa abertura à participação do grupo que naquele momento administrava a escola, menos centralizador das decisões que os anteriores. A harmonia entre as opiniões desse grupo e os princípios defendidos pelo governo do

4 O CPERS, em assembléia geral no ano de 1999, indicou aos sindicalizados o boicote ao processo da $\mathrm{CE}$, como forma de pressionar o governo para atender as reivindicações da categoria. 
Estado para a educação parecem ter facilitado a introdução de novas propostas na escola.

Mesmo contando com o envolvimento de todos os segmentos, quando se questionou sobre os pais ficou evidente sua menor participação. Porém, foram bastante receptivos à implantação da progressão parcial. De acordo com o professor, o mesmo parece ter ocorrido em relação aos alunos: a receptividade dos pais foi muito boa. Até pela questão do investimento também dos pais; puxa, um ano de estudo perdido. E pros alunos também.

Assim como ocorreu na Escola Paulo Borges, na Escola Gilberto Alves a alteração na organização curricular pressupunha maior empenho e responsabilidade com a escola. Algo que, segundo o professor Gustavo, é cobrado pela equipe administrativa e deve ser assumido por toda a escola. Trata-se de uma necessidade de assumir o compromisso com a aprendizagem e o sucesso dos alunos.

Nós estamos cobrando isso dos alunos que estão em progressão, que é a questão do compromisso com a escola, né? A questão da disciplina também; quer dizer, nós temos que nos comprometer com essa escola, com esse projeto de escola, com a progressão nos estudos, com a possibilidade de um tempo menor nas contas dos estudos.

Assim como a Escola Gilberto Alves, a Escola Fábio Costa também implantou a progressão parcial. Se essas escolas têm em comum a fixação da progressão, o mesmo não pode ser dito do processo que conduziu a tal modificação. Na Escola Gilberto Alves, a progressão, implementada a partir do debate com a comunidade, é percebida como um entrave à evasão, ou seja, evitar que o aluno abandone os estudos por ter sido reprovado em uma série. Já na Escola Fábio Costa, constituiu praticamente uma imposição da CRE.

Os dados coletados na Escola Fábio Costa permitem concluir que o processo lá instalado ia de encontro a todos os princípios e diretrizes afirmados na CE. Havia uma recomendação da CRE para que as escolas que não optassem pela mudança na organização curricular (ciclos, progressão) pelo menos reduzissem a nota mínima para a obtenção da aprovação. Consternado com essa orientação, o diretor - professor Lúcio revelou ter sido "obrigado" a alterar a média da escola e a implantar a progressão parcial:

Tu não podia sair fora da média cinco. Na progressão que foi implantada aqui, através de um regimento outorgado pelo Conselho Estadual de Educação, o aluno não é mais reprovado, ele vai passando pra série seguinte e fica em dependência em até duas disciplinas. Então, a gente quis mudar isso, porque a comunidade quis e aí 
não foi aceito dentro da própria Coordenadoria de Educação, porque eles dizem que tem que ser mais amplo e eles não enviam pra SEC nem pro conselho o regimento que não esteja mais ou menos assim, padrão da média cinco em todas as escolas do Estado. Aí, eu comecei a questionar: "Mas como?" Se nós fizemos dois plebiscitos aqui na escola, e os pais dos alunos, 99\% optaram pela média sete, porque sempre a média foi sete aqui, optaram pela média sete. E a progressão, no início eu não aceitava pelo seguinte: por falta de espaço; por nós não termos recursos humanos, que sempre falta, até, vamos dizer assim, no regime regular, né, no ensino médio e fundamental, também não poderia retirar. Então, o aluno que que acontecia? O aluno só que não é alfabetizado na $1^{a}$ série é que reprova. Os demais passam pra série seguinte, mas ficam trabalhando as deficiências, que ficaram do ano anterior.

Mesmo conseguindo agregar um número muito significativo de pessoas da comunidade nos debates sobre o projeto pedagógico e o regimento escolar, ficou evidente o caráter persuasivo das relações estabelecidas entre a administração da escola e os demais segmentos. O professor Lúcio argumentou que mostrou para a comunidade as "vantagens e desvantagens" da redução da nota. Então, a partir disso, a maior parte optou por manter a média sete. Tal decisão não foi aceita pela CRE, que indicava a média cinco. Tal recusa causou a indignação do professor Lúcio: vários questionamentos começaram a surgir e a gente começou a se perguntar, mas até onde nós temos o direito de colocar no papel aquilo que a comunidade quer?

Assim, estabeleceu-se um conflito entre a escola e a CRE. Após muitas idas e vindas do regimento e do projeto pedagógico, a média ficou em seis.

Nós ficamos surpresos na hora em que não passou nosso regimento na Coordenadoria, que teria que ter média cinco, que não poderia ser mais, ou seis, aqui até a gente deixou o seis, mas sete não poderia ser. Então, quer dizer que a constituinte é aquela coisa assim, ó, é a vontade da comunidade, aquilo que a comunidade quer, [...] quando chegou na prática dentro da escola, simplesmente, aí era só sobre leis, pareceres. A gente traçou junto com os pais, alunos, professores... E não foi aceito tudo aquilo que a comunidade queria; então é uma coisa praticamente pronta.

No caso da Escola Fábio Costa, a CRE contestou as decisões e as reivindicações da comunidade escolar, determinando modificações no regimento e no projeto pedagógico. Percebe-se que o debate desencadeado na escola conduziu a opções conservadoras e excludentes. A luta pela manutenção de uma média elevada e a resistência à progressão, mesmo que parcial, demonstraram que o fato de contar com a participação de 
todos os segmentos não fez com que a decisão da coletividade fosse a mais democrática.

Ainda neste debate, é preciso considerar a postura indiferente da equipe administrativa da Escola Selma Moraes. Nessa escola de ensino fundamental incompleto, a professora Loiva revelou que chegaram a conversar rapidamente sobre possíveis alterações na organização curricular, entretanto optaram por não realizar mudanças e permanecer no sistema seriado. A professora atribuiu isso ao fato de a escola ainda resistir ao novo e a mudanças. Vale ressaltar que essa é uma escola que nunca faz greve, que não participa de nenhuma mobilização e que não teve praticamente envolvimento nenhum com a CE.

A falta de informação, a infra-estrutura inadequada, os baixos salários, enfim, poder-se-ia aqui enumerar uma série de argumentos utilizados pelos educadores contra os ciclos. Comumente, tais argumentos são ouvidos tanto naqueles locais onde se mantém uma estrutura seriada quanto naqueles onde foi imposta a implementação dos ciclos. No primeiro caso, os argumentos são usados para conservar a estrutura tradicional, e, no segundo, para justificar a impossibilidade da manutenção dos ciclos.

É interessante considerar essa questão, pois na Escola Paulo Borges primeiramente se optou pelos ciclos pelos motivos já expostos, para depois, paralelamente à sua implementação, avaliar os problemas que surgiriam. Parece ser necessário haver um compromisso dos sujeitos que integram a comunidade, dada a quantidade de elementos que precisam ser mobilizados quando a escola se propõe a romper com uma determinada organização. Durante o estudo, percebeu-se um notável destaque para a importância do compromisso dos segmentos que integram a comunidade com qualquer mudança promovida na escola. Entretanto, exceto quando diretamente questionados, poucos entrevistados mencionaram o papel, a responsabilidade e o compromisso do Estado no provimento de meios que assegurem à escola pública uma educação de qualidade. É como se bastasse o compromisso dos segmentos para assegurar melhores condições de ensino.

Outro aspecto que precisa ser considerado é a questão da autonomia. Se, por um lado, a SE foi coerente com a defesa da autonomia (debate presente nas diferentes etapas da $\mathrm{CE}$ ) ao não impor às escolas qualquer tipo de organização curricular e, principalmente, ao não obrigar as escolas a participar do processo de elaboração da CE, por outro, constatou-se uma intolerância em relação aos índices estabelecidos pelas escolas para que os alunos obtivessem aprovação. Observou-se, também, uma certa pressão para que as escolas adotassem a progressão continuada, ou seja, os alunos avançassem para a série seguinte, mesmo que não 
tivessem obtido o índice mínimo para aprovação em determinada disciplina.

Essas constatações parecem revelar uma intenção de eliminar a reprovação dos currículos escolares de forma gradual. Isto é, primeiro diminui-se a média, segundo implementa-se a progressão parcial. Talvez, com tal estratégia os diferentes segmentos que integram as unidades escolares apresentassem menos resistência à implementação de um sistema de ensino em que não houvesse reprovação. Essa prática parecia ser a intenção dos gestores.

De acordo com a representante do governo Luísa, era necessário reverter os percentuais de evasão e repetência das escolas estaduais do Rio Grande do Sul. Isso implicava levar os educadores e a sociedade em geral a perceberem as causas do insucesso escolar:

E um trabalho forte no sentido de qualificar o ensino pra superar os percentuais de evasão e repetência. [...] Nós ainda temos altos índices de evasão e repetência, por conta de que muitas vezes a comunidade nem sequer se dava conta de que o ato educativo e as condições sociais estavam levando muitos alunos a não concluir nem o ensino fundamental [...]. Há muitos educadores que muitas vezes não se dão conta que a sua própria prática pedagógica está levando à evasão escolar [...].

Com isso, percebe-se que havia uma vontade dos gestores de eliminar a retenção de alunos. Porém, parece ter faltado uma vontade política desencadeadora de uma ação mais condizente com os princípios expostos no início do processo da CE, de democratização da escola pública, já que a decisão sobre a eliminação da reprovação foi delegada às escolas.

Percebeu-se que as escolas que optaram pelos ciclos foram "premiadas" pelas coordenadorias regionais de educação com redução de carga horária em sala de aula para os professores; acompanhamento mais intenso dos educadores da CRE; organização de horários de reforço; criação de laboratórios de aprendizagem e garantia de tempo para reuniões e estudos. Como já dito, providências que assegurem um ensino de qualidade são necessárias sempre. Isto é, a adoção dos ciclos não pode ser requisito para essas ou outras medidas e vice-versa.

$\mathrm{O}$ acesso ao debate, à discussão sobre os efeitos nefastos da reprovação na vida de um sujeito não conduziu a mudanças mais expressivas na educação da rede pública estadual gaúcha. Prova disso é que nenhum dos princípios ou das diretrizes resultantes de todo o processo da CE aponta para a extinção da reprovação da estrutura curricular da rede estadual do Rio Grande do Sul. 
Não constituiu propósito deste artigo fazer um exame exaustivo das profundas transformações que podem ocorrer na escola pública a partir da adoção de critérios de avaliação não-seletivos e excludentes, até porque isso fugiria ao propósito central da pesquisa que originou esta discussão. Tentou-se demonstrar que a participação da sociedade em um amplo processo de discussão e debate sobre a escola pública propiciou uma reflexão sobre os processos de avaliação até então adotados (caracterizados pela retenção de alunos) que resultou em mudanças na estrutura curricular de algumas poucas escolas. Tais modificações foram definidas a partir da vontade daqueles que integram os segmentos da comunidade escolar. Isso significa, que as opções por mudanças estão condicionadas a uma série de fatores de ordem social, econômica, política e cultural e, dessa forma, parece urgente o aprofundamento do debate sobre a avaliação e a retenção, dada a heterogeneidade de situações vividas nas escolas estaduais do Rio Grande do Sul.

\section{REFERÊNCIAS BIBLIOGRÁFICAS}

ARROYO, Miguel G. Ofício de mestre: imagens e auto-imagens. 6. ed. Petrópolis: Vozes, 2002.

BARRETTO, Elba Siqueira de Sá; MITRULIS, Eleny. Trajetória e desafios dos ciclos escolares no País. Estudos Avançados: dossiê educação. São Paulo, v. 15, n. 42, p. 103-140, maio/ago. 2001.

FREIRE, Paulo. Pedagogia da autonomia. 12. ed. São Paulo: Paz e Terra, 1999.

MENDES, Valdelaine da Rosa. Participação na definição de uma política educacional: mecanismo de controle público sobre as ações do governo? São Paulo, 2005. Tese (dout.) Faculdade de Educação, Universidade de São Paulo.

MOREIRA LEITE, Dante. Promoção automática e adequação do currículo ao desenvolvimento da criança. Revista Brasileira de Estudos Pedagógicos, Brasília, DF, v. 84, n. 206/207/208, jan./dez. 2003.

PARO, Vitor Henrique. Reprovação escolar: renúncia à educação. São Paulo: Xamã, 2001. 
RIO GRANDE DO SUL. Secretaria da Educação. Caderno 1 da Constituinte Escolar: texto base. Porto Alegre: Corag, 1999.

Secretaria da Educação. Princípios e diretrizes para a educação pública estadual. Porto Alegre: Corag, 2000.

Recebido em: maio 2006

Aprovado para publicação em: setembro 2006 